\title{
"ELLA HALLARÁ TAMBIÉN COSAS EXTRAÑAS": FIGURACIONES DE LA MUJER Y LO FEMENINO EN PARRA
}

\author{
María Luisa Fischer \\ Hunter College of The City University of New York
}

\begin{abstract}
¿Es la poesía de Parra otra manifestación del habitual machismo del siglo pasado? ¿O merece leerse de una manera más sofisticada? No existe una respuesta fácil. Este artículo explora el ambiguo territorio de lo femenino en el trabajo del antipoeta.
\end{abstract}

Is Parra's poetry another manifestation of 20th century machismo? Or should it be read from a more sophisticated viewpoint? There is no easy answer. This article explores the ambiguous treatment of women in the anti-poet's work.

MARÍA Luisa Fischer (Santiago, 1959). Licenciada en literatura en la Universidad de Chile. Ph.D. en lenguas y literaturas hispánicas en Boston University. Profesora asociada en el Departamento de Lenguas Romances de Hunter College of The City University of New York. Ha publicado los libros Historia y texto poético: la poesía de Antonio Cisneros, José Emilio Pacheco y Enrique Lihn (Concepción: Lar, 1998) y Neruda: construcción y legados de una figura cultural (Santiago: Editorial Universitaria, 2008). Hoy desarrolla una investigación acerca de las formas que asume la memoria de la dictadura en la poesía chilena contemporánea, con especial atención a la obra de Raúl Zurita. Email: maria.fischer@hunter.cuny.edu 
D eleer la poesía de Parra examinando las figuraciones de la mujer R y lo femenino obliga a un estado de alerta constante. Sabemos, aunque no está de más insistir en ello, que quien habla en sus poemas es endeble e inseguro, contradictorio y resbaladizo; es una voz inestable, que dice y se desdice. Desde los inaugurales Poemas y antipoemas de 1954, y de manera definitiva en Versos de salón de 1962, no se trata de sujetos centrados y únicos, sino que de emisores cambiantes y múltiples. Aunque hay excepciones, incluso cuando aquéllos adquieren los contornos aparentes de personajes tampoco se conforman en entidades de coherencia psicológica. Como explica Niall Binns, "los hablantes y protagonistas antipoéticos son sujetos desprovistos de su esencia humana — su ilusión de esencia humana—, deslumbrados y fragmentados por el bombardeo de imágenes y lenguajes que los atraviesan". ${ }^{1} \mathrm{Su}$ habla no es fluida ni transparente: no paran de hablar, pero tartamudean o lo hacen con la lengua pegada al paladar. Son habladores y se dejan traspasar por los lenguajes sociales y sus convenciones discursivas, que los develan y exhiben, al tiempo de mostrar cuán frágil es la pretensión de alcanzar una identidad cohesiva y completa. Acaso toda la poesía de Parra no se dedica más que a este develar vehemente de la palabra de la tribu. Según William Rowe, "lo que se ofrece es un diagnóstico de las funciones culturales de los diferentes lenguajes y, además, la posibilidad de transitar entre ellos sin ser poseído por ninguno en particular". ${ }^{2}$ Por todo esto, no se valen ni la simple identificación de los dichos de los textos con las opiniones del autor, ni una interpretación mimética que reúna sin más textos y realidad social. Por el contrario, si se persigue fidelidad con las conquistas de la poesía de Parra, se hace necesario leer poniendo atención a las dinámicas de la elocución de los textos, las que permean y, más aún, constituyen lo dicho. Como obra que devela los lenguajes sociales, resulta un material privilegiado para observar las representaciones de género, un ámbito que por definición se encuentra determinado social y culturalmente. Así, en el examen de las figura-

${ }^{1}$ Niall Binns, "Los medios de comunicación masiva en la poesía de Parra", Revista Chilena de Literatura 51 (1997), 88.

2 William Rowe, "Nicanor Parra: The Poem as Amoeba", en Poets of Contemporary Latin America. History and the Inner Life (London: Oxford University Press, 2000), 31. La traducción (y las que siguen) son mías. El original es: "What is offered is a diagnostic of the cultural functions of different languages and the possibility of moving among them without being possessed by any one of them". 
ciones de la mujer y lo femenino que me propongo realizar intento inscribirme conscientemente desde mi condición de mujer en la actividad interpretativa, como "sujeto sexuado que incorpora a la hermenéutica interpretativa su experiencia genérica" ${ }^{3}$ Me centraré en apenas cinco poemas de Poemas y antipoemas, con el objetivo de observar en ellos el significado de lo femenino (y lo masculino) en tanto "mitos culturales cambiantes". A partir de esa base de análisis textual, propongo conexiones con momentos posteriores del itinerario de la obra de Parra.

Al contrario de los estereotipos heredados que asocian lo masculino con lo racional, el pensamiento lógico y lo abstracto, los hablantes antipoéticos, anclados en la cotidianidad más pueril, se encuentran asediados por las pasiones y no siguen un hilo de pensamiento nítido, sino que, por el contrario, se mueven en círculos o sin rumbo fijo, se enredan y contradicen. Al final de la tercera y última parte del libro inaugural de 1954, la sección en la que se arriba en propiedad al antipoema, ${ }^{5}$ se presentan cinco poemas ubicados en rápida sucesión enfocados en reconstruir, a través de discursos que se asemejan a una confidencia patética emitida paradójicamente en alta voz, los hechos desgraciados que el hablante sufrió en una época pasada de su vida. Se trata de "Recuerdos de juventud", "El túnel”, "La víbora", "La trampa" y "Las tablas", que tienen en común, además de su calidad narrativa episódica, el ubicar al protagonista en interacciones conflictivas con mujeres, ya sean las amantes o su voz perturbadora al otro lado del teléfono, unas tías explotadoras o la propia madre a la que se golpea en un sueño. En "Recuerdos de juventud" (OC 1: 44-45), ${ }^{6}$ tanto "la gente" como "los individuos" hostigan al personaje que, como consecuencia, siente que se hunde "en una especie de jalea" (OC 1: 44). En una gradación de asedios que se entrega en versos consecutivos, el tercer miembro de la

${ }^{3}$ Lola Luna, Leyendo como una mujer la imagen de la mujer (España: Anthropos, 1996), 19.

${ }^{4}$ Gabriela Mora, "Crítica feminista: Apuntes sobre definiciones y problemas", en Theory and Practice of Feminist Literary Criticism, ed. Gabriela Mora \& Karen S. Van Hooft. Ypsilanti (MI: Bilingual, 1982), 4.

${ }^{5}$ René de Costa, "Para una poética de la antipoesía", introducción a Poemas y antipoemas de Nicanor Parra (Madrid: Cátedra, 1988), 18-19.

${ }^{6}$ En adelante, consigno fecha de la primera publicación y cito por los dos tomos de 2006 y 2011 de Nicanor Parra, Obras completas \& algo + (Barcelona: Galaxia Gutenberg - Círculo de Lectores, 2006 y 2011). Indico para ellos OC 1 y OC 2, respectivamente, y página correspondiente. 
serie son "las mujeres", que parecen ubicarse en una categoría aparte de las dos anteriores, pero que, como ellos, también lo rechazan y manipulan, despiadadas. El personaje se desplaza "de un lado a otro" a través de espacios urbanos, a merced de las "miradas de odio" de ellas, que le provocan sentimientos contradictorios para los que no guarda defensa alguna. Las dolencias del pobre tipo sin rumbo ni manera de salvar la distancia que lo "separa de los otros abismos" (OC 1: 45) tienen que ver con eros y la muerte, que, como ocurre en muchos textos parrianos, se presentan imbricados y se confunden: ${ }^{7}$ los movimientos de caderas son "bailes fúnebres" que envían al hablante agotado y agobiado a los cementerios en busca de respuestas que, por supuesto, no encuentra. El sujeto parece entender oscuramente la conexión entre un erotismo que lo aleja de y conecta con el límite definidor de la muerte, si lograra comunicarse con los otros, pero las mujeres no consiguen llegar a ser el espejo convocante del otro, ya que han sido ubicadas por él mismo en una categoría excluyente que lo expulsa. Todo el poema tiene el aspecto de una confesión melodramática y autoindulgente, en la que se reúnen elementos disonantes: el debut del sujeto no es en un cine o teatro, como correspondería, sino que en un salón de clases; allí se siente "como un herido de bala" (OC 1: 45) de los westerns, quien, en lugar de arrastrarse por el polvo, lo hace por los ateneos; a continuación cruza un umbral que es apenas de "una casa particular" (OC 1: 45), en vez de ser el límite entre un mundo y otro. Las sutiles desviaciones del decir remiten al carácter de escenificación distorsionada que se expone desde el título mismo: lejos de la dulce evocación prometida de un tiempo ido, tenemos la desorientación extremada en una ciudad de indiferentes que se esconden tras el periódico o un taxi. Si hubiera un atisbo de profundidad en las interacciones entre hombre y mujer, en un verso paralelo a la mención "de los otros abismos", que aluden por contraste a encuentro y comunicación, "el trozo de cebolla visto durante la cena"

${ }^{7}$ Hay una serie de textos con lenguaje de corte popular que ligan la erótica y la muerte, muchas veces en la línea de la imagenería de origen medieval de la muerte como doncella que seduce. No puedo investigarla en el presente trabajo, pero me parece un área fructífera para observar las representaciones de la mujer en Parra. Ver, por ejemplo, la sección VI de "Cartas del poeta que duerme en una silla" en Obra gruesa (1969) (OC 1: 233), el artefacto "La muerte es una puta caliente" (OC 1: 337), "La muerte supersónica", "Debajo de mi cama" y "El poeta y la muerte" (OC 2: 253, 275 y 283) en Hojas de Parra (1985). 
$(O C$ 1: 45) de la estrofa final lo desmiente con la fuerza de lo pedestre y lo risible.

Como si la estructura misma de Poemas y antipoemas estuviera encargándose de enseñar a leer para aprender en qué consiste la diferencia específica del antipoema, en oposición a la evocación nostálgica de escenas amorosas de un tiempo juvenil asociado al entorno pueblerino de, por ejemplo, "Es olvido" o "Cartas a una desconocida", en la tercera sección del libro el vínculo del hablante masculino con la mujer es extremadamente conflictivo. Al abandonar el espacio rural evocado con el lenguaje más armonioso de los poemas mencionados, el desencuentro brutal con la mujer tiene lugar en la ciudad, la que todavía puede llegar a expulsar al recién llegado de su seno, como sucede en "El túnel". En este sentido, Poemas y antipoemas puede entenderse como una obra que en sus estructuras subyacentes dramatiza y tematiza las consecuencias en la subjetividad del desarraigo de la inmigración del campo a la ciudad de la primera mitad del siglo XX y la confrontación de visiones e ideologías que este traslado supone. En vez del escarceo erótico de los poemas de la serie que examino, en "El túnel" (OC 1: 46-48) las malvadas son unas tías de otra época y lugar, que explotan emocional y económicamente al sobrino, quien declara que debió abandonar sus estudios para hacerse cargo de ellas de vuelta en el pueblo. No debemos pasar por alto que aunque "túnel" señala la situación del sujeto y que traspasarlo es convencionalmente una metáfora visual de la superación, también, metonímicamente, al entrar en él se alude a la penetración. De este modo, podríamos arriesgar que en el poema se instala un plus: el de una potencial relación incestuosa. En el relato retrospectivo del hablante, las "temibles damas" intentan su particular seducción inicial ofreciendo el amparo de ideas de otra época, con "alusiones mitológicas" y menciones a "filósofos medievales" y "sabios de la antigüedad" (OC 1: 46). Sin embargo, el pretendido consuelo de la cultura se expone como parte de una mascarada: junto con los nombres prestigiosos se cuelan los de los "vecinos de la localidad" (OC 1: 46). El relato del sobrino fluctúa entre el rechazo de autoafirmación y la victimización autocompasiva. $\mathrm{Su}$ lenguaje es paródicamente patético y lo expone como depositario de una maraña de ideas diversas y poco asimiladas (espiritismos, teosofía, escritura automática, pero también la ideología del progreso individual), que seguramente lo hacen proclive a 
caer en las redes que las señoras le tienden. Las alusiones van entretejiendo la atmósfera de una época donde conviven sin síntesis resabios culturales que podemos identificar con los del modernismo hispanoamericano, mano a mano con los desarrollos posteriores, al tiempo que se exponen las ansiedades que provoca en el muchacho provinciano estudioso la confrontación entre culturas de prestigio y cultura de masas. La gran cantidad de referencias temporales que va organizando el relato señala la idea del tiempo experimentado subjetivamente: los cuatro años vividos en El Túnel se perciben como horas, semanas, meses, años y, finalmente, "siglos de prisión vividos por mi alma" (OC 1: 47). La sentencia melodramática es devaluada de inmediato porque las centurias transcurren, ridículamente, "[...] En el interior de una botella de mesa!" (OC 1: 47). En paralelo al in crescendo temporal que va revelando el entramado denso de la confusión del protagonista, el momento definitorio del presente se construye a través de menciones a estímulos visuales que refractan, cubren, contienen y, finalmente, nublan e impiden la visión. ${ }^{8}$ Las redes que despliegan "aquellas matronas", tramadas con fantasías extrañas, dolores simulados y falsas promesas, conllevan, como es recurrente en los textos de Parra que exponen las relaciones hombre-mujer, un intercambio económico o comercial concreto: el pobre sobrino se ve forzado a "trabajar para ellas / En faenas de agricultura / En compraventa de animales" (OC 1: 47). Se trata de una obligación devaluada ya que es impuesta, de un modo contradictorio, "tácitamente", como también es devaluada de manera sutil la revelación del engaño que han montado las "ancianas histéricas". Subrayando el riguroso carácter visual del relato de sus tribulaciones, al espiar "por la cerradura" (OC 1:47) el sobrino se entera de que la tía paralítica no es tal, sino que "[c]aminaba perfectamente sobre la punta de sus piernas" (OC 1: 48). Es fácil desatender la desviación del decir que representa el verso citado, ya que a primera vista no siempre nos percatamos de que la seudoinválida no se desplaza en la punta de sus pies, como rezaría la expresión correcta. Las leves distorsiones del lenguaje, junto con sus estructuras temporales y visuales redundantes, van provocando

${ }^{8}$ En las estrofas cinco a siete, el hablante mira "a través de un prisma"; las imágenes de las tías forman "una malla impenetrable"; vive como si estuviera dentro "de una campana de vidrio"; y por su habitación se filtra "una especie de vapor de agua" que hace "todo invisible" (OC 1: 47). 
desajustes que deben alertar a la lectora a observar el antipoema por el ojo de la cerradura, sospechando de sus personajes y examinando el relato aparentemente directo de ellos. Este aspecto central de la poética del antipoema lo explica William Rowe, al afirmar que "muchos de los poemas de Parra dramatizan los intentos que el hablante realiza, a través de procedimientos retóricos, de mantener el control. El oyente no está presente como una figura que habla, pero los lectores se ubican en posición de oyentes virtuales, con la libertad de discernir las maniobras del hablante". 9

Al final de su cuento, el sobrino parece haber encontrado la luz del otro lado del túnel y termina afirmando que, a consecuencia del descubrimiento, "volví a la realidad con un sentimiento de los demonios" (OC 1: 48). El poema concluye abruptamente con un verso que declara de manera taxativa la superación de la situación de abuso a la que el personaje se sometió. Pero la sospecha instalada por su propia habla desajustada, desviada, invita a dudar del despertar de conciencia y el retorno a la realidad, así como a temer de las emociones que se despiertan en él. Acaso el poema mismo en su conjunto está construido alrededor del expandir, examinar y desarmar la frase hecha "ver la luz al otro lado del túnel". Al otro lado encontramos sólo la ambivalencia de un relato retrospectivo que no se conforma con nociones simples ni con lo que consideramos como realidad ni con las emociones.

Las tías explotadoras y embaucadoras representan el espejo deformado del romance familiar que se despliega de modo contenido y dulce en los (pocos) conmovedores poemas que Parra les dedica a algunas de las mujeres de su familia. Como apunta Iván Carrasco, se trata de "un tipo de personaje de origen campesino, de condición modesta, caracterizado por su sabiduría y vitalidad...". ${ }^{10}$ El lenguaje hondo y despojado de los sentimientos en textos de distintas etapas de la actividad creativa - como el dedicado a la hija Catalina en 1954 ("Catalina Parra" OC 1: 9-10), a la hermana cantora en 1969 ("Defensa de Violeta Parra", OC 1: 226-231) o a la madre en 1985

\footnotetext{
${ }^{9}$ Rowe, "The Poem as Amoeba", 38. Texto original: "Many of Parra's poems dramatize a speaker's attempts, through rhetorical devices, to retain control. The listener is not present as a figure who speaks, but readers are placed in the position of virtual listeners, with freedom to see through the maneuvers of the speaker".

${ }^{10}$ Iván Carrasco, Nicanor Parra. Documentos y ensayos antipoéticos (Santiago: Universidad de Santiago, 2007), 181.
} 
("Clara Sandoval", OC 2: 279-280)— se ofrece en contraste con los personajes femeninos amenazantes e imprevisibles y las emociones contradictorias que inspiran en sus contrapartes masculinas de la serie que examino. La capacidad de ejercer lenguajes del sentimiento de tan diverso cariz e intencionalidad resulta en sí misma de interés. Como desarrollo a continuación, Parra somete la idea convencionalizada del amor romántico y las relaciones entre géneros, en un medio social marcado por las ideas represoras y represivas del pecado cristiano, a un desmantelamiento despiadado que no ofrece el consuelo de mejores alternativas o creencias. Pero hay un lugar para la celebración amorosa de las mujeres de la familia en los textos, que acaso se destaca más en contraste con la visión amarga y satírica que caracteriza la mayor parte de la producción parriana a este respecto. Cuando a partir de los años noventa la obra del poeta se vuelca a la exploración visual, aparece en Las bandejitas de la Reina un personaje que se identifica como el Hablante Lírico —o Don Nadie o Mr. Nobody, en una variante juguetona de la noción que toma prestada de Fernando Pessoa, según la cual "los poetas no tienen biografía" (de $O C$ 1: 182)—, a quien se representa con una simple ilustración de un corazón con ojos, brazos y piernas. Según declara Parra en una entrevista del año 2006, el palote fue evolucionando: al principio, "tenía cabeza no más [...] pero me di cuenta de que era muy pretencioso, que el hombre es más corazón que cabeza, más tinieblas que luz, y que el personaje paradigmático tenía que ser un corazón con patas, porque eso es el hombre". ${ }^{11}$ Los polos de la racionalidad y los sentimientos definen a esta figuración visual de la voz lírica, que habla desde los afectos como la dimensión determinante del hombre, la que se asocia a oscuridad y no a las luces de la cabeza o razón. Postularía que esta declaración habría que considerarla al pie de la letra en lo que tiene de reveladora. Parra ha ido reformulando una concepción en que humanidad se confundía con género masculino, como corresponde al lenguaje habitual de la cultura que él explora, pero que también lo traspasa y habla a través de él mismo. Si los personae de la serie de Poemas y antipoemas que examino son deficitarios porque se encuentran a merced de manipulaciones y emociones, y luchan infructuosa e incesantemente por retomar el control de situa-

${ }^{11}$ Entrevista de Macarena García G., El Mercurio, 9 de julio de 2006, citada por Niall Binns, "Notas. Sobre Obras públicas", en Parra, OC 2: 1134. 
ciones que se les escapan, en la reformulación posterior se comienza a asumir, sin rebelarse contra ella y con la liviandad que implica imaginarse como un "corazón con patas", la condición vulnerable, precaria y "sentimental" que los define.

"La víbora" es un texto privilegiado para examinar algunas de las dinámicas de género a las que aludo. Con "La trampa" comparte ambientes, atmósferas y el antihéroe sojuzgado por una presencia femenina seductora. Han recibido una gran atención crítica desde su publicación temprana en 1948 en la antología de Hugo Zambelli (13 poetas chilenos), la que, de revisarse en detalle, podría en sí misma dibujar los contornos de una conciencia en proceso de cambio con respecto a la representación de género en la poesía chilena. Como muestra, veamos tres de esas evaluaciones críticas. Para Ricardo Yamal, "La víbora" "se basa en el estereotipo de la mujer fatal que ejerce su poder sobre el sujeto relator [...] y se parodia la situación total". ${ }^{12}$ Para Iván Carrasco, el poema,

antipoetiza el modelo de la mujer como ángel de seducción, que se conserva no sólo en la tradición literaria sino también en el verosímil [...] de la cultura hispanoamericana, [у ...] lo superpone con el estereotipo de la femme fatale [...] una mujer dominante, materialista, interesada, que incluye connotaciones diabólicas. Esta mujer es un ser ambiguo, atrayente y repugnante al mismo tiempo, de una belleza de Medusa, [...] que en lugar de ofrecer goce y placer a su pareja, sólo le causa problemas, lo esclaviza y lo explota sexual y económicamente. ${ }^{13}$

En "La víbora”, según Karen S. Van Hooft,

[e]1 mito del amor romántico [...] se destruye a través de su presentación en negativo. El uso de la ironía, de un lenguaje coloquial trillado y del énfasis en los motivos de la comunicación fallida, la distancia y la frustración sexual demuestran la vacuidad del amor tradicional como forma de comunicación humana. [...] Se muestra cómo el ejercicio de los papeles sexuales tradi-

12 Ricardo Yamal, Sistema y visión de la poesía de Nicanor Parra (España: Albatros - Hispanófila, 1985), 33.

${ }^{13}$ Carrasco, Nicanor Parra, 184. 
cionales, papeles que se definen por estereotipos, es, en último término, negativo, porque esos papeles son claramente muy limitantes. ${ }^{14}$

La víbora del poema se conecta, como observan los críticos, con mitos, modelos culturales y estereotipos profundamente arraigados, los que son expuestos y parodiados. Yamal y Carrasco se enfocan más en las cualidades anómalas de la víbora, mientras pierden de vista parcialmente el hecho de que, en paralelo y de manera quizá tan fundamental como el accionar de la seductora, el emisor se retrata a sí mismo en su propia habla.

En el relato del pobre galán de "La víbora" se despliegan expectativas con respecto a conductas consideradas "normales", para frustrarlas acto seguido. Reconocemos frases hechas del repertorio convencional del lenguaje amoroso en la idea del amor como condena y prisión; o en las referencias a la luz de luna, el encanto de una mujer, a una voz amada, la caída de "las primeras hojas del otoño" (OC 1: 50) o el construir un nido para la pareja. Sin embargo, estos elementos tópicos se aplican a objetos deformados en más de un sentido. La relación íntima que describen está signada por "notas discordantes" que muestran la impotencia y descontrol del hablante. Su sometimiento es simultáneamente contradictorio y total: es un proveedor laborioso, pero recibe préstamos de la mujer; sin pausa hace trabajos de oficina, pero delinque para ella; se entrega a una actividad sexual frenética, pero se encuentra a merced de cuestiones metafísicas; vive de la caridad pública, pero es extorsionado y conminado a pagar sus deudas por su amante; está prisionero en las redes de ella, pero es el cónyuge de "su verdadera mujer" (OC 1: 51). La lectora que debe barajar este cúmulo de alternativas absurdas descubre que, en realidad, representan menos episodios particulares

${ }^{14}$ Karen S. Van Hooft, "Vipers, Victims, and Virgins: Women and Their Relationships with Men in the Poetry of Nicanor Parra", en Theory and Practice of Feminist Literary Criticism, ed. Gabriela Mora \& Karen S. Van Hooft (Ypsilanti, MI: Bilingual, 1982), 274. La cita original es: "The myth of romantic love is also destroyed by its negative presentation. The use of irony, of hackneyed colloquial language, and the stress on the motives of failed communication, distance, and sexual frustration demonstrate the emptiness of traditional love as a form of human communion. [...] The playing of traditional sexual roles, roles that are defined by the stereotypes, is shown to be ultimately negative, for such roles are clearly very limiting". 
de un triángulo amoroso que se desarrolla a través del tiempo - en el recuento, el hablante declara que sufrió por largos cinco años-que un caleidoscopio que espejea las ansiedades masculinas frente a una mujer asertiva que maneja su dinero, cuerpo y desplazamientos por la ciudad. Con respecto al ámbito del dinero, el poema se ubica en el contexto del cambio de roles y expectativas del Chile de la segunda mitad de los años cuarenta, cuando la mujer profesional independiente asoma como una presencia definida en la estructura económica del país. ${ }^{15} \mathrm{La}$ relación está signada por una variedad de intercambios mercantiles que cubren un espectro de actividades, desde las legales a las delictivas, del trabajo asalariado al gran capital, de la propiedad al despojo. Hay menciones de centavos, negocios, préstamos y libros de cuentas. Hay libelos periodísticos y amenazas de demandas judiciales. El trabajo y el dinero están marcados por la enajenación y el abuso, mientras el personaje se mueve entre los polos del bienestar y la miseria aparentes y/o inminentes, siempre en el intento de satisfacer los requerimientos de su amante. Este contexto mercantilizado es claramente anómalo para una relación amorosa, de acuerdo con los ideales del amor romántico, pero también en relación con el papel social masculino incontestado de proveedor económico, ya sea en el matrimonio sancionado socialmente, como en "la casa chica". En el ámbito del cuerpo, la víbora posee el suyo a voluntad, baila desenfrenada, ofrece su boca, no le da "un instante de tregua" (OC 1: 49) al amante, se pasea desnuda o con un taparrabos por la ciudad. ${ }^{16}$ Además, invirtiendo los roles tradicionales del orden patriarcal que mantiene un control férreo sobre los cuerpos femeninos, la víbora ejerce el tipo de celos posesivos que generalmente son parcela del género masculino, mientras maneja a gusto y “con [...]

${ }^{15}$ Como explican Simon Collier y William F. Sater en A History of Chile, 1808-1994. (UK: Cambridge University Press, 1996), 287: “[b]y the 1930s and 1940 s, a female presence was becoming altogether more visible in the professions, in the health services, in education, in the arts, in journalism, and on the radio". [Es decir: "hacia los años treinta y cuarenta, la presencia femenina se hacía en general más visible en las carreras profesionales, los servicios de salud, las artes, el periodismo y en la radio".].

${ }^{16}$ Karen S. Van Hooft observa, en este sentido, que "Canción" sería el poema contrapartida de la sexualidad femenina retratada en "La víbora", en cuanto presenta el deseo de la receptiva "repentina doncella" (OC 1:26) como dependiente de la agencia masculina que le otorga el placer (doloroso) de la iniciación sexual (Van Hooft, "Vipers, Victims", 267-268). 
espíritu práctico" (OC 1: 50), el acceso a su propio cuerpo. En el ámbito de los desplazamientos urbanos, como el hablante de "Recuerdos de juventud", la víbora va de un lado a otro de la ciudad, pero lo hace no como señal de descontrol, sino como índice de libertad. No se mantiene restringida a "la santidad del hogar", sino que visita a su amante en su departamento, arrienda "a medias" con él piezas de pensión y compra, finalmente, una parcela donde planea edificar una pirámide para "los últimos días" (OC 1: 50) de los dos. No la familia, pero sí la propiedad privada es asunto de una mujer. Sus entornos "naturales" no son los domésticos ni los de la familia, sino los espacios públicos urbanos: café danzantes, parques y plazas. Encontramos, sin embargo, la presencia de otros recintos en los que se emplaza la historia amorosa. Son amenazantes e improcedentes, como corresponde al cementerio cercano a la pensión en "un barrio de lujo" (OC 1: 51), y al matadero próximo a la parcela donde se construirá la pirámide funeraria de los dos. Además de aproximar la actividad de los amantes a los sitios de la ciudad donde se negocia la muerte, estas referencias distorsionadas acentúan la atmósfera de derrota de las declaraciones finales del hablante, quien, a pesar de todo, se queda con la última palabra. Frente al intento final de seducción de la víbora, la historia de la relación concluye con un encuentro "lleno de notas discordantes" que se traslada, en el discurso directo de la réplica del amante, al presente:

Basta de sandeces, repliqué, tus planes me inspiran desconfianza,

Piensa que de un momento a otro mi verdadera mujer

Puede dejarnos a todos en la miseria más espantosa.

Mis hijos han crecido ya, el tiempo ha transcurrido,

Me siento profundamente agotado, déjame reposar un instante,

Tráeme un poco de agua, mujer,

Consígueme algo de comer en alguna parte,

Estoy muerto de hambre,

No puedo trabajar más para ti,

Todo ha terminado entre nosotros. (OC 1: 51)

En este remate del poema, una secuencia de frases independientes va acelerando el ritmo del verso. La declaración diferida de la existencia de una esposa e hijos de la víctima de las manipulaciones de la víbora lo transforma, de personaje inocente y merecedor de lástima, a uno 
mucho más patético. El poema concluye en las necesidades fisiológicas del hambre, la sed y la fatiga, subrayando el sustrato básico de su gran pequeña tragedia, que, al exagerar los lugares comunes de la seducción, expone las ansiedades masculinas frente a una mujer que maneja su dinero, cuerpo y desplazamientos.

"La trampa" expone unas ansiedades paralelas a las que identificamos en "La víbora", pero en vez de la mediación del dinero - que ubica al personaje femenino en el mundo - se enfoca en la que ejerce un medio de comunicación, el teléfono, cuando transmite la voz de la mujer deseada. Se trata de uno de los antipoemas tempranos de 1948, donde se imagina el efecto disolvente de un medio de comunicación en la psiquis del hablante. Niall Binns identifica Versos de salón como el libro donde se registra el impacto de los mass media en Parra, "cuya textualidad muy particular se debe en gran parte a una asimilación poética de los medios de comunicación masiva". ${ }^{17}$ Binns propone la presencia del molde específico y sistemático de la radio en los modos de expresión del volumen de 1962. En contraste, en "La trampa" el medio no define los modos de dicción y las formas del poema, que se organiza en largos versos narrativos que no buscan reproducir los modos de la comunicación telefónica, sino que describen en detalle los efectos en el hablante, antes, durante y después de la conversación con la voz literalmente descarnada de su amante. El teléfono es una de las esferas de atracción que va desarmando al sujeto del poema, mientras él ejerce intentos vanos de comunicación. Es interesante destacar en este poema un rasgo común a la poética parriana. En "La trampa" se entremezclan esferas contradictorias que asedian al sujeto. El personaje, que tiene la fantasía de ejercer voluntaria y conscientemente una dirección predeterminada, se encuentra, como en "El túnel", a merced del tironeo de fuerzas dispares: unos métodos seudocientíficos y otros seudooníricos; la noción del alma humana y su promesa de trascendencia; las exigencias de una vida "moderna" y las pequeñeces de la misma con sus "cretonas amarillas" (OC 1: 53) y "la dueña de la pensión” (OC 1: 54); la fisiología de su propio cuerpo y, en particular, de la voz. No hay manera de integrar ni sintetizar las esferas diversas y, como consecuencia, el sujeto se muestra desarticulado. La atracción erótica representa la esfera de

\footnotetext{
${ }^{17}$ Binns, "Los medios de comunicación”, 83.
} 
mayor fuerza, de la que en vano se busca distraerse a través de las investigaciones y el accionar peregrinos que emprende el personaje.

Cada una de las etapas de la comunicación telefónica se describe con todos sus pormenores y efectos en el hablante: la expectativa, el momento conativo, la conversación misma, lo que sucede al cortar. Identidad, voz y cuerpo parecen jugarse por entero en el intercambio. De hecho, en el poema se efectúa más de una sustitución: la de la identidad individual por la voz, y, en particular, por su transmisión diferida a través del teléfono, y de toda la conversación como sustituto del mermado e insatisfactorio encuentro erótico. En los segundos mientras la llamada está por comunicar, el yo se percibe dividido en dos y se figura "como un esqueleto de pie" (OC 1: 53), mientras los sonidos previos a la respuesta del otro lado del auricular le provocan "el efecto de las máquinas perforadoras de los dentistas" (OC 1: 53), transpira y se imagina tartamudeando. Luego, y de manera angustiosa, no consigue articular palabra y declara que "mi lengua parecida a un beefsteak de ternera / Se interponía entre mi ser y mi interlocutora / Como esas cortinas negras que nos separan de los muertos" (OC 1: 53). De manera paradójica, en el poema se persigue la posibilidad de identificarse y ser en la propia voz mientras, al mismo tiempo, se muestra la dificultad del intento. Éste se plantea como un imposible, no sólo en el momento crítico del inicio de la comunicación telefónica, sino que también durante el desarrollo de la misma, cuando los intercambios producen efectos indeseables en el personaje y en su interlocutora. La conversación íntima, el "nombre de pila" escuchado en la voz del otro, el intercambio erotizado del diálogo telefónico son ocasiones de "catástrofes ... deprimentes" (OC 1: 54) para el personaje, las que se extienden a citas que tienen lugar en dos sitios opuestos: en una fuente de soda, casual y sin consecuencia, o "en la puerta de una iglesia de cuyo nombre no quiero acordarme" (OC 1: 54), que sugiere el lazo de un matrimonio indeseado, tipificado en la frase acuñada de Cervantes. Al enfocarse meticulosamente en la fenomenología del diálogo incorpóreo a través del auricular, en "La trampa" se escenifican no sólo los avatares neuróticos del personaje que habla, sino que, más en general, la relación dificultosa entre la identidad y la voz y el deseo (y la imposibilidad) de aunarlas en la comunicación con el otro. Aunque se invierte toda la energía en perseguir la comunicación, la "lengua que se interpone" entre los amantes alude a la imposi- 
bilidad de salvar el abismo que los separa y encontrar así "una respuesta desde el otro extremo del mundo" (OC 1: 53). No sólo se interpone una lengua literal e individual (el "beefsteak de ternera", grueso y ridículo), sino una lengua social que, a través y en el personaje, habla de una dinámica del discurso amoroso que se desenvuelve entre sujetos distintos y distantes, esas categorías aparte y excluyentes (la gente, los individuos, las mujeres) que se exponían en "Recuerdos de juventud". Resulta de interés constatar que en el momento de producción del poema, hacia fines de los años 40, la telefonía aún no se masificaba en domicilios particulares y constituía un medio de comunicación "especial" e incluso, insólito. Su figuración en el texto que analizo subraya la rareza de una comunicación que no está interferida por los moldes culturales de género que poseen al personaje y a su habla.

Como una forma de desarrollar las conclusiones de este ensayo, una revisión breve de "Las tablas" nos permite atraer a la discusión la fundamental temática del molde religioso cristiano, del cual no se puede escapar aunque sea éste meramente "ambiental". ${ }^{18}$ En el poema se narra de manera abrupta un sueño y con ese marco, por tanto, se permite explorar diversos tabúes. En un desierto, que marca el texto de reminiscencias bíblicas, el yo protagonista golpea violentamente a una mujer — su "traje estaba empapado de sangre" (OC 1: 59)—, la que pronto se descubre que era su madre. Lo hace "hastiado" de sí mismo (OC 1: 59). Lo hace, de nuevo, como en "La víbora", asediado por necesidades básicas: quiere dormir, tiene frío y, además, no logra pensar con claridad. Lo hace también porque sí, porque "era necesario hacer algo, / hacer fuego, hacer un poco de ejercicio" (OC 1: 59). Dialoga, a continuación, con varias voces acusadoras que lo confrontan: rocas, pájaros, con "Mi dios que me miraba hacer estas cosas" (OC 1: 59) y, finalmente, con "las tablas de la ley" que le señalan sus pecados. La economía del poema no es simbólica, las cosas nombradas "son meras cosas". ${ }^{19}$ Bostezando y aburrido, el personaje declara: "Entonces yo me volví de nuevo a mi dama / y le empecé a dar más firme que antes" (OC 1: 60). El lenguaje coloquial con su molde ya acuñado señala lo

${ }^{18}$ Niall Binns, Un vals en un montón de escombros. Poesía hispanoamericana entre la modernidad y la postmodernidad (Nicanor Parra, Enrique Lihn) (Bern: Peter Lang, 1999), 76.

${ }^{19}$ Rowe, "The Poem as Amoeba", 52. 
"normal" de la ocurrencia de golpear a una mujer; además, se desliza el cambio nominativo de madre a dama, cargando el sueño de matices incestuosos, como correspondería a una fantasía de corte freudiano. ${ }^{20}$ En este momento del relato, el personaje declara que tiene que hacer algo "para no caer dormido" y decide quemar la imagen del dios o ídolo para abrigarse un poco. La variación en el nombre que denomina la deidad implica una devaluación del monoteísmo y su dios omnipotente. Así como en los sueños se pasa sin solución de continuidad de una cosa a otra, la dicción del texto varía bruscamente, desde el lenguaje vernáculo chileno cuando saca "una caja de fósforos" para encender el fuego, a uno admonitorio con tonos religiosos. Al quemar la imagen del ídolo, desaparecen también las tablas de la ley y, con ellas, las rocas y "[m]i madre que me había abandonado" (OC 1: 60). Como sucede en los cuatro poemas analizados hasta aquí, un final brusco señala el fracaso, sin dar ninguna explicación de los hechos, que se ofrecen sin más a la interpretación de la lectora. El personaje declara en el último verso, simplemente, que "ya no podía más", y el poema termina. El marco del sueño no se rompe (quizás despertarse sería tan intrascendente como dormirse, ya que en ello se insiste al interior del sueño). Sólo queda el personaje vacío, sin ley, ni dios, ni madre. De manera congruente con "Soliloquio del individuo", que cierra el volumen entregando una historia poética apretada del hombre moderno, en "Las tablas" se plantea la situación de desamparo del sujeto sin la protección de ninguna creencia superior, la que se devalúa pero que enmarca el sueño. La ley mosaica a la que aluden "las tablas" no rige ni se sostiene en el espacio onírico sin preceptos.

En el poema, las relaciones del personaje con sus contrapartes femeninas alcanzan una última faz conflictiva y se ubican, de manera

20 Aunque, como observa Rowe, en "The Poem as Amoeba", 52-53: "for Freud, a dream is the symbolic expression of a desire. But what if the desire is to survive (rather than to make a mark or be marked)? Parra subverts Freud's system of controls by turning it inside out: the symbolic is not inherent to the psyche - nor even to language - but a force of social control to be evaded for the sake of survival in an authoritarian society". Es decir: "Para Freud, el sueño es la expresión simbólica de un deseo. Pero, ¿qué ocurre si el deseo es sobrevivir (en vez de dejar una marca o ser marcado)? Parra subvierte el sistema de controles de Freud al darlo vuelta: lo simbólico no es inherente a la psiquis —ni siquiera al lenguaje-, sino una fuerza de control social que se evade para sobrevivir en una sociedad autoritaria". 
explícita, en una de las temáticas de Parra más constantes en la zona del "diagnóstico de las funciones culturales de los diferentes lenguajes" al que se refiere William Rowe: el de la religión, y del cristianismo en particular. ${ }^{21}$ El punto está planteado de manera sucinta y cómica en Artefactos (1972), donde se propone, por ejemplo, que "para no ir demasiado lejos, tomemos el caso de Adán y Eva" (OC 1: 389). Junto al artefacto que impreca y encara de modo acusatorio, "raza de fornicadores, católicos tenían que ser" (OC 1: 396), estas frases explosivas recolectadas del entorno social acusan una noción de sexualidad marcada por el pecado, cuya propulsora en la Caída ha sido y continúa siendo la mujer. Este viejo molde es, sin duda, expuesto y criticado en la dicción vehemente de los artefactos, pero el modelo mismo lo podemos identificar en el andamiaje del texto parriano. A este respecto, Karen S. Van Hooft examina la solución compensatoria que se plantea en "Los vicios del mundo moderno" y en "Soliloquio del Individuo", los que funcionan como una especie de poética de la antipoesía. Luego del largo y variadísimo collage de vicios en que consiste el poema, la estrofa final propone, frente a la "gran cloaca" del mundo (OC 1: 57), un turbado camino compensatorio o, como sugiere Federico Schopf, un aferrarse a lo que esté disponible para obtener aunque sea la ilusión de felicidad: ${ }^{22}$

Tratemos de ser felices, recomiendo yo, chupando la miserable

[costilla humana.

Extraigamos de ella el líquido renovador,

Cada cual de acuerdo con sus inclinaciones personales.

¡Aferrémonos a esta piltrafa divina!

Jadeantes y tremebundos

Chupemos estos labios que nos enloquecen;

La suerte está echada.

Aspiremos este perfume enervador y destructor

${ }^{21}$ Se trata de un marco de discurso omnipresente desde el inaugural Poemas y antipoemas hasta las Obras públicas de 2006, con el icónico cartelito "Voy y vuelvo" (OC 2: 844) colgado de una cruz de madera. En el libro de 1954, los poemas "Desorden en el cielo", "San Antonio" (OC 1: 21 a 23) desmantelan, con el molde del verso popular, la institución y la imaginería católicas, mientras que "Advertencia al lector" y "Solo de piano" (OC 1: 33-34 y 40) atacan el dogma cristiano y exponen los presupuestos de un mundo sin dios, respectivamente.

${ }^{22}$ Federico Schopf, "Prólogo" a Poemas y antipoemas (Santiago: Nascimento, 1971), 35, citado en Van Hooft, "Vipers, Victims", 276. 
Y vivamos un día más la vida de los elegidos:

De sus axilas extrae el hombre la cera necesaria para forjar el rostro de sus ídolos.

$\mathrm{Y}$ del sexo de la mujer la paja y el barro de sus templos. [...] (OC 1: 58)

Ante la sugerencia que identifica en esta estrofa conclusiva a la mujer (o al sexo) como una salvación burlona para la humanidad, Van Hooft precisa con justeza que "es difícil ver que el objetivo sea la 'salvación', especialmente para la mitad femenina de la humanidad. Por el contrario, parecería simplemente que se trata de una receta para la sobrevivencia masculina...". ${ }^{23}$ "Soliloquio del individuo" predice el dictum del artefacto y pone a operar la historia del génesis bíblico, colocando a la mujer como apéndice de la costilla de Adán, es decir, "en su lugar" tradicional. Con el extraer, chupar y aspirar, verbos que representan aspectos de la actividad sexual, se propone que del cuerpo de la mujer surge la energía para la creatividad, las creencias y el (pobre) consuelo. Sobre el último verso citado arriba, Van Hooft sostiene que "es la más clara referencia a la explotación de la mujer", y le sugiere "el lugar común observado frecuentemente, según el cual los hombres, no las mujeres, crean la cultura oficial; se percibe a la mujer en una capacidad creativa sólo a través del producto de su sexualidad". ${ }^{24}$ Los hablantes de Parra declaran este tipo de lugares comunes acerca de las dinámicas de género, pero estimo que al hacerlo, como personajes devaluados e incongruentes que son, utilizan y activan los estereotipos, pero también se exhiben apresados por y en ellos. La lectora que revisa las figuraciones de la mujer y lo femenino en Parra identifica, a no dudar, una mirada que privilegia la óptica masculina, la que se forja desde nociones heredadas de lo masculino y lo femenino. Pero si la consideramos en las dinámicas que los textos promueven, es posible evaluar esa óptica con la distancia crítica de una lectura desmitificadora.

${ }^{23}$ En el inglés original: “... it is difficult to see that 'salvation' is the goal, especially for the female half of the humanity. Rather, this would seem to be simply a desperate recipe for male survival...". Van Hooft, "Vipers, Victims", 276.

${ }^{24}$ En el inglés original: “... is the clearest reference to the exploitation of women" [y sugiere] "the often observed common-place that men, not women, create our official culture; woman is seen as being creative only through the product of her sexuality". Van Hooft, "Vipers, Victims", 276-277. 
Por el carácter inestable de los pronunciamientos de los hablantes, la poesía de Parra invita a la lectora atenta a un género de lectura sospechosa. Como una máquina de significar que va exponiendo agudamente el funcionamiento de los lenguajes sociales, el decir desacreditado de los personajes puede leerse, desde una óptica de género, como indicio e incluso denuncia irónica de lógicas sexistas afincadas en tradiciones de larga data.

Parra ha ido reformulando la óptica férreamente machista que proponía la transformación radical del decir poético con una fórmula (y una ilustración) sexistas, en el artefacto bien conocido en el que se afirma que:

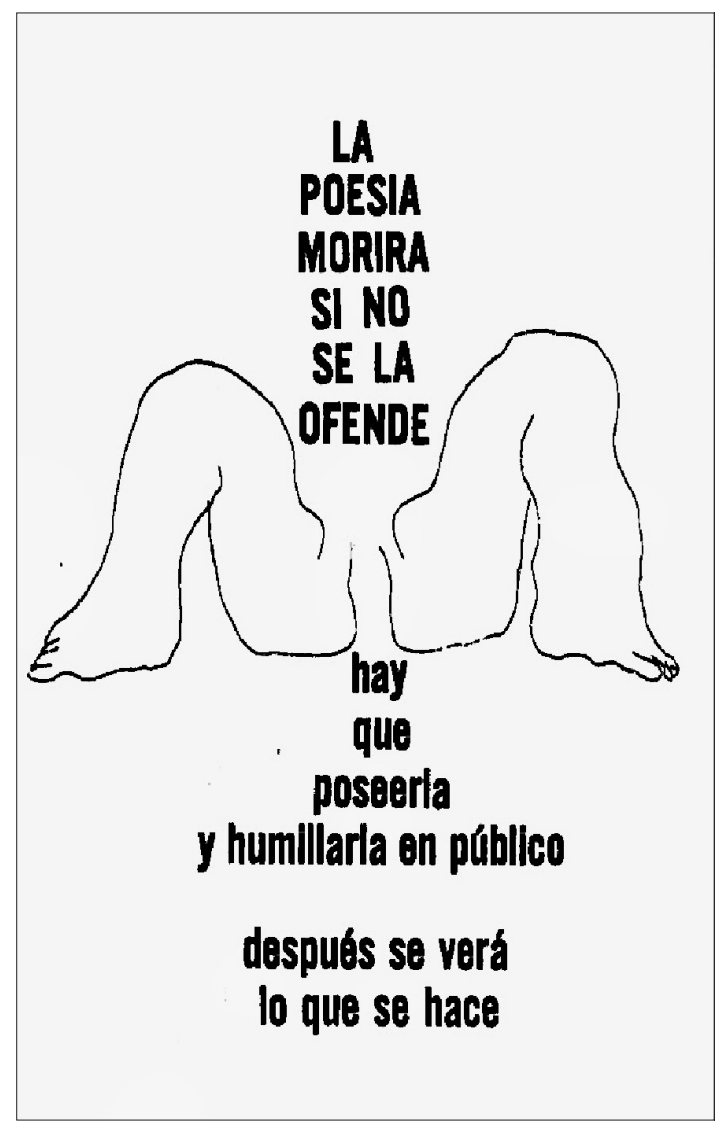

Fuente: OC 1: 395. 
El camino destructor de la antipoesía se aplica de manera agresiva a la metáfora que identifica poesía con mujer. A ella se la violenta sexualmente en público para revitalizar el discurso poético anquilosado y retomar el vínculo con el público lector (que no puede no ser sino excluyentemente masculino). El artefacto que se propone como discurso transgresor y transformador se basa en la identificación metafórica de sexualidad con violencia ejercida sobre el cuerpo femenino. En contraste, hacia el final de "Mai mai peñi (Discurso de Guadalajara)", de 1991, el primero de los Discursos de sobremesa (2006), que se ofrece con ocasión de recibir el premio de literatura Juan Rulfo, se encuentra "La mujer". Se trata de un texto emitido por una voz más cercana a la voz del escritor ${ }^{25}$ y que expresa un cariz autoevaluativo que me parece evidente. En él se ofrece lo que creo es una autoexégesis implícita con respecto a figuraciones previas de la mujer en la propia obra: ${ }^{26}$

Hay un punto

Que no podemos dejar de tocar

En ocasión tan álgida como ésta

Voy a cederle la palabra a un muchacho

Que en pleno siglo XIX

Sabía ya lo que estaba diciendo

Comillas:

Cuando se rompan las cadenas que esclavizan a la mujer

Cuando ella pueda vivir por sí misma y para sí misma

Cuando el hombre

sujeto abominable hasta aquí

${ }^{25}$ Como explica María Ángeles Pérez López, en una introducción a la obra de Parra imprescindible, "su voz como escritor no es una voz autorizada, pierde el prestigio que hubiese podido tener y evita cualquier empatía a través de diversos procesos de desublimación. Aparece constantemente devaluado y se autodevalúa cuando pide al lector que queme este libro". María Ángeles Pérez López, "La antipoesía de Nicanor Parra. Poesía en tiempos de zozobra”, introducción a Páginas en blanco de Nicanor Parra (Salamanca: Ediciones de la Universidad de Salamanca y Patrimonio Nacional, 2001), 55.

${ }^{26}$ Léase en esta línea "Bien", inmediatamente a continuación a "La mujer", como un poema que a su vez se refiere al anterior: "El sol miró para atrás / Ésa es la verdad de las cosas / Se demostró que 2+2 son 4 / O algo x el estilo / Sursum corda / Ahora sí que se fue la bolita / + vale tarde que nunca / Habría dicho la Violeta Parra..." (OC 2: 596). 
La haya liberado

La mujer también accederá a lo desconocido

Sus constelaciones de ideas diferirán de las nuestras?

Ella hallará también cosas extrañas

Insondables

horribles

deliciosas

Que nosotros sabremos apreciar

Que nosotros sabremos comprender

(Rimbaud, Carta del vidente) (OC 2: 595)

Parra le cede la palabra al poeta visionario francés para que desde el siglo XIX (le, nos) hable en el presente, consciente acaso de la ironía del hecho. Hace suya una visión que entiende la subordinación femenina como efecto social de la dominación masculina, aunque continúa asegurando que la agencia liberadora todavía no les pertenece en propiedad a ellas, sino que será fruto del regalo benefactor de ellos. El acceso a la creatividad, la posibilidad de ejercerla y desarrollar una mirada propia de la mujer se plantean como pregunta retórica. Queda pendiente, sin embargo, en la exégesis de este poema aparentemente tan directo, otras preguntas que no son retóricas: ¿a quiénes señala en los versos finales ese "nosotros" que sabrá apreciar y comprender las extrañas cosas femeninas? ¿A la humanidad compuesta por quiénes? ¿El futuro anunciado por Rimbaud está para Parra todavía por arribar?

En el Diccionario de la lengua española se define "toro" en una de sus acepciones como: "2. hombre muy robusto y fuerte", pero "vaca" como: "1. hembra del toro". A estas definiciones marcadas por el lenguaje de la tradición patriarcal alude el artefacto "Toro - vaca de sexo masculino" (OC 1: 551) que desarma las jerarquías y subordinaciones de género acudiendo a la imagen cargada del bovino. Sí, pero con un Parra que estimula la libertad para que las lectoras disciernan las maniobras de los hablantes, y con un Parra para los próximos cien años, también podríamos revertir con humor la fórmula en un léxico más inclusivo: "Vaca - toro de sexo femenino". 


\section{OBRAS CITADAS}

Binns, Niall. "Notas. Sobre Obras públicas". En Obras completas \& algo + / Vol. 2, de Nicanor Parra. Barcelona: Galaxia Gutenberg - Círculo de Lectores, 2011.

- Un vals en un montón de escombros. Poesía hispanoamericana entre la modernidad y la postmodernidad (Nicanor Parra, Enrique Lihn). Bern: Peter Lang, 1999.

— - "Los medios de comunicación masiva en la poesía de Parra". Revista Chilena de Literatura 51 (1997): 81-97.

Carrasco, Iván. Nicanor Parra. Documentos y ensayos antipoéticos. Santiago: Universidad de Santiago, 2007.

Collier, Simon y Sater, William F. A History of Chile, 1808-1994. UK: Cambridge University Press, 1996.

Costa, René de. "Para una poética de la antipoesía". Introducción a Poemas y antipoemas, de Nicanor Parra, ed. René de Costa. Madrid: Cátedra, 1988, 9-40.

Luna, Lola. Leyendo como una mujer la imagen de la mujer. España: Anthropos, 1996.

Mora, Gabriela. "Crítica feminista: Apuntes sobre definiciones y problemas". En Theory and Practice of Feminist Literary Criticism, ed. Gabriela Mora \& Karen S. Van Hooft. Ypsilanti, MI: Bilingual, 1982, 2-13.

Parra, Nicanor. Obras completas \& algo $+/$ Vol. 1, ed. Ignacio Echevarría. Barcelona: Galaxia Gutenberg - Círculo de Lectores, 2006.

—. Obras completas \& algo $+/$ Vol. 2, ed. Ignacio Echevarría \& Niall Binns. Barcelona: Galaxia Gutenberg - Círculo de Lectores, 2011.

Pérez López, María Ángeles. "La antipoesía de Nicanor Parra. Poesía en tiempos de zozobra", introducción a Páginas en blanco, de Nicanor Parra. Salamanca: Ediciones de la Universidad de Salamanca y Patrimonio Nacional, 2001, 9-82.

Rowe, William. "Nicanor Parra: The Poem as Amoeba", en Poets of Contemporary Latin America. History and the Inner Life. London: Oxford University Press, 2000, 29-77.

Van Hooft, Karen S. "Vipers, Victims, and Virgins: Women and Their Relationships with Men in the Poetry of Nicanor Parra". En Theory and Practice of Feminist Literary Criticism, ed. Gabriela Mora \& Karen S. Van Hooft. Ypsilanti, MI: Bilingual, 1982, 256-278.

Yamal, Ricardo. Sistema y visión de la poesía de Nicanor Parra. España: Albatros Hispanófila, 1985. EP 